\title{
(In)credible Subjects: NGOs, Attorneys, and Permissible "LGBT Asylum Seeker" Identities
}

In this paper, I demonstrate how statist logics concerning acceptable lesbian, gay, bisexual, and/or transgender (LGBT) immigrants permeate civic spheres, creating new forms of exclusion for asylum seekers in the United States. Existing research on U.S. asylum policy and procedures as they pertain to LGBT claimants suggests that a "gay enough" litmus test typifies U.S. Customs and Immigration Services (USCIS) adjudications, such that officers expect claimants to engage in conspicuous consumption of stereotypical commodities and culture, and to appear visibly "LGBT," through gender non-conformity, or by being “out.” My analysis focuses on the social, as well as legal, lives of LGBT asylum seekers in the United States. Drawing on ethnographic and interview data collected at specialist NGOs, I argue that limited ideas about LGBT subjectivity often structure NGO workers' attitudes and practices in ways that echo USCIS criteria for granting asylum. I demonstrate how NGO client selection and intake processes subtly yet effectively replicate existing adjudication norms, and prevailing ideas about $L G B T$ subjectivity. Within ostensibly non-governmental spaces, LGBT asylum seekers experience suspicion, surveillance, and pressure to conform to NGO workers' expectations of "credible" claimants. Contrary to NGOs' stated intentions, these processes extend, rather than challenge, existing barriers to asylum.

[asylum, NGOs, sexuality, United States, immigration] 
From 1965 until 1990, U.S. immigration policy explicitly excluded so-called "sexual deviates" from entering the United States. Since 1994, however, the United States has recognized sexual or gender minorities as members of a potentially persecuted social group, eligible for asylum under immigration law. Over the past decade, a small but notable number of scholars have engaged critically with U.S. asylum policy and procedures as it pertains to such cases (cf. Morgan 2006; Berger 2009; Lewis 2013). Kimmel and Llewellyn (2012) conclude that a "gay enough" litmus test typifies lesbian, gay, bisexual, or trans (LGBT) asylum adjudication, such that interviewing officers expect claimants to engage in conspicuous consumption of mainstream LGBT commodities and culture - from films and magazines to nightclubs and community centers—and to display visible evidence of LGBT identity, such as being publicly "out," or adopting a gender non-conforming appearance (Berger 2009; Murray 2016). These expectations are coupled with the general requirements of all asylum seekers to demonstrate sound character, have a clean record, and provide "compelling evidence" in support of their claim (USCIS 2011).

The exemplary LGBT asylum seeker in many ways mirrors the productive, domesticated, and depoliticized consumer that Lisa Duggan (2002) identifies as the now-acceptable face of "homonormative" LGBT subjectivity in the United States, or the "good gay citizen" (Bell and Binnie 2000; Stychin 2004). As such, 
official measures to exclude "sexual deviates" from entering the U.S. may be read as having evolved rather than abated, with LGBT asylum adjudication understood as a strategy of containment, or selective allowance.

In this paper, I focus on specialist non-governmental organizations (NGOs) providing services to LGBT asylum seekers in the United States, and consider how such groups contest, echo, or extend governmental logics about who should be granted asylum in the United States. First, I address pro bono attorneys' client selection criteria and intake processes, noting which people are granted access to services, and on what basis. Second, I discuss how staff at social service NGOs regard and treat clients, following their own ideas about "credible" LGBT cases. Throughout, I use close readings of interviews to parse out pro bono attorneys' and NGO staff's ideological assumptions and stated motivations for their work, and to consider their perspectives in relation to my asylum seeker and asylee (a person who has been granted asylum) interlocutors' lived experiences. In doing so, I show how discourses about LGBT asylum seekers that circulate between and are reproduced within governmental, media, and social spheres can erase nonhomonormative ways of being LGBT, and consequently marginalize those unable to conform to service providers' expectations. I conclude that limited ideas about LGBT subjectivity structure NGO workers' attitudes and practices in much the same way as they shape U.S. Customs and Immigration Services (USCIS) criteria 
for granting asylum. As such, these NGOs may be read as extending rather than challenging existing legal barriers to asylum for LGBT claimants-an outcome that has notable consequences for all asylum seekers, and more broadly for nonnormatively LGBT people living in the United States.

My data are drawn from sixteen months of ethnographic research with asylum seekers, asylees, NGO staff and volunteers, and attorneys, conducted between 2012 and 2014 at three sites: Nottsborough, New England; the California Bay Area; and Washington D.C. In each location, I accompanied asylum seeking interlocutors through their daily routines, both within and beyond NGO spaces. I also spent time in NGO offices and attended fundraising and educational events, keeping extensive field notes and collecting organizational reports and promotional materials. I interviewed twenty-two service providers from eight organizations. While some asylees worked for these NGOs, the vast majority of staff and volunteers - and all of the attorneys - were U.S. citizens. My forty asylum seeker and asylee interlocutors hailed from fifteen countries, primarily in the Caribbean, East Africa, Russia, and the Middle East. Thirty had received support — housing, legal representation, travel cards, or stipends — from a NGO that worked exclusively with LGBT asylum seekers. Ten had either relied on personal resources and networks to navigate the asylum process, or had received aid from a patchwork of non-specialist organizations. 
I use pseudonyms for individuals and organizations throughout this article. I also use the term "LGBT," while noting that not all people fleeing persecution of their sexuality or gender identity self-identify as lesbian, gay, bisexual or trans. I do not suggest an a priori U.S.-centric reference point for my interlocutors' diverse sexual and gender subjectivities. The acronym has however become accepted shorthand for such asylum claimants within law and policy, media, and - to a lesser extent—scholarly circles. As I focus on discursive constructs and the transferal of ideas between those spheres, I want to pay attention to this norm, rather than contest it here. Moreover, my interlocutors identified as L, G, B and/or $\mathrm{T}$, with one exception who eschewed all identity labels. Accepting my interlocutors' self-identifications at face value — rather than assertively naming them as "queer" or otherwise "non-LGBT"-further demonstrates how limited definitions and imaginaries used within and around the asylum system can deny individuals" claims to "LGBT" identity on their own terms.

\section{Permissible Subjectivities (or, "Winnable Cases")}

The Rainbow Immigration Coalition (RIC) was established in 1994 to provide legal services to LGBT immigrants, particularly bi-national same-sex couples. Following the 2012 repeal of the Defense of Marriage Act, RIC remarketed itself as the preeminent legal service provider and advocacy organization for LGBT 
asylum seekers. Backed by a dedicated Public Relations team, it became the go-to voice for journalists and policy researchers covering LGBT asylum. In 2013, RIC raised over two million dollars from private and foundation donors. Other nonprofit organizations provide pro bono counsel to LGBT asylum seekers, as do a range of lawyers' associations, small NGOs, law school clinics, and private legal firms. None boasts as high a profile as RIC.

Each year, these organizations field thousands of calls and emails from LGBT people seeking counsel, information, or advice about seeking asylum. Demand for services outstrips capacity, as the U.S. government does not provide legal aid to asylum seekers. Organizations decide to take on a potential client, if capacity allows, on the basis of an intake interview. During the interview, a staff member — usually a junior or trainee—first runs through an asylum eligibility checklist: Have you applied for asylum before? Have you ever been deported? Do you have a criminal record? Next, they ask about childhood and early sexual encounters, same-sex relationships, involvement in LGBT groups back home, and experiences of persecution. In effect, the interviewer runs through the official asylum application (Form I-589), replicating a USCIS asylum interview—albeit with more compassionate framing and less apparent skepticism. The intake can nonetheless be traumatizing for the interviewee, who must relay deeply personal information to a stranger. 
The post-intake debrief is usually limited to an explanation of "next steps"namely that a senior attorney will review the notes and decide whether or not to take on the client. If they decide against, most organizations will provide a referral, a list of other potentially useful organizations, or brief guidance on submitting an asylum claim without legal counsel—with the caveat that qualified representation greatly increases a person's chance of winning asylum. If they believe a potential claimant will really struggle to obtain asylum, the attorney may advise against submitting an application at all. Private attorneys rarely turn down potential clients, on any of the above grounds, privileging individuals who have significant financial resources.

Irene Garcia, a junior staff member at a prominent Bay Area LGBT legal services NGO, offered instructive insight into how her organization decided which cases to accept:

From [the intake], I will do, like, a small memo for the immigration project, then they will say, "Oh, this is a very strong case, we'll like to take it on," or, "Oh, this has some kind of complicated issues." I mean if they've been deported in the past, if there's like a bar, then it will go through our pro bono attorney who'll say, "Better not touch this one, there's not really much we can do." 
I was struck by how Irene framed "strong" cases in opposition to "complicated" ones that her organization did not want to "touch." Some of my interlocutors had technically complex cases: they had been deported, or had married someone of the opposite-sex, or had missed the official one-year filing deadline. Their claims were nonetheless compelling, and well-supported. I had also seen interlocutors struggle to articulate their experiences, or to recall precise dates and event details during intake interviews. I wondered if Irene's organization would take on such cases. As we continued talking, I considered the "success rates" I had seen posted by LGBT asylum organizations in a new light:

Siobhán: [when I see] the percentages granted, like a ninety-eight percent success rate, I'm thinking how there's a maybe a filter system there, where [organizations] don't take on the cases that they think are going to lose. Would you say that [accepting clients is] about "winnable" cases, in part?

Irene: I don't know if I can answer that, to be honest. Only because I don't make the final decision. But, I mean, a lot of our cases-- or some of our cases, not a lot, but some of the cases that we take on, we have possible doubts about. We're like, "Oh, this will be either/or. I guess we'll just run with it and see what happens. We'll 
just have to fight tooth and nail to extend our ground." I think a really important thing to highlight is that in the 20 years [our organization] has been here, we've never lost a case. It's been an amazing run.

I did not doubt that the attorneys with whom Irene worked advocated sincerely for their clients. Yet her acknowledgment that they took on only "some... not a lot" of cases that they "had doubts about" winning revealed that likelihood of success factored highly in their decision-making. Other specialist legal service providers had similarly amazing runs. RIC, for example, reported a ninety-nine percent asylum "win rate." Its website further stated that, while some cases were referred elsewhere, RIC handled "the most difficult cases" in-house. It did not reveal how many people it declined to represent. At first blush, such figures seem commendable, far outstripping the success rate of asylum claims in general. ${ }^{1}$ In light of Irene's comments, however, organizations' near-perfect records appear to be as much the product of exceptional legal representation as they are a predictable outcome of a weighted client-selection process.

There is therefore a circular logic to the statistical evidence that a person is more likely to win asylum if they have legal representation: if attorneys are accepting the cases most likely to be successful, high win rates are effectively guaranteed. 
As "winnability" is determined by how closely a case meets established legal norms, it follows that specialist pro bono attorneys advocating for LGBT asylum seekers are more regularly choosing to comply with, rather than challenge, the status quo of USCIS asylum adjudication mechanisms that have been repeatedly found to discriminate against non-normatively LGBT claimants (Berger 2009; Rehaag 2009).

Carol Rotman, an experienced immigration attorney and salaried staff member of an East Coast pro bono legal organization, offered me a candid assessment of the subjective contours of the client selection process:

I can only take about ten percent of cases that come to me. Even people I believe, I can't take all the cases. [...] I'd say eighty percent of them I believe their case, maybe even ninety. I'm just throwing out figures here. Maybe one out of ten I turn away because I don't think they have a case, and then the rest I turn away because I can't do all the cases, and I try and place as many as I can with other organizations. [...] Sometimes I just have to choose [a] case because someone's living in a homeless shelter and then another person isn't. I just have to figure out who's the most vulnerable. And then also, I'm a human being too. Sometimes I just take cases 
because I feel-- I just like the case. I really want to help this person, I like them. I like the particular cause that it's serving. But, yeah, I turn away probably ninety percent of the cases that come in. And then I'd say probably fifty percent of those that I turn away, I'm able to place somewhere.

Throughout our conversation, Carol stressed that she was speaking from personal experience, not for other attorneys. I heard other legal advocates draw similar conclusions, however, albeit more obliquely. Carol acknowledged that she only took on clients whom she "believed"-which she framed as synonymous with "having a case," despite its subjective weight. Her selection criteria were also guided by a sense of obligation to support people she saw as especially needy and "vulnerable," and who she felt other organizations might not support. Carol continued:

I'm particularly partial to the LGBT cases but there's so many asylum seekers who are not LGBT who have really, really, good, sympathetic cases. And it's really hard to place the political cases right now because — as far as asylum lawyers go — they're becoming run of the mill. The LGBT ones, they're sexy, they're excitingthere's these [anti-homosexuality] laws coming down right now, as 
you're doing the case. And then there's the run-of-the-mill political activist who's been tortured and I can't place those cases. It's [also] easier to find funding and lawyers for the LGBT cases. $[\ldots]$ the people that I have an impossible time finding lawyers for are the male, young, political activist who was jailed and tortured from-Uganda is the main place I see people from. It's impossible. So I end up taking a lot of those cases too, because they're incredibly sympathetic. [...] And then Central American ones are mostly domestic violence and gang related. [...] I think we're just so accustomed to Central Americans here or something, it's not as exciting to represent someone who's Central American. And also, the domestic violence cases don't seem to be ones that attorneys want to take. To get a volunteer attorney to do a case it's got to excite them in some way, and the domestic violence ones, they just don't.

Carol's frank assessment reveals how deeply pervasive ideas about deserving, "sympathetic" immigrants inform funding for, and accessibility to legal aid for asylum seekers. Heath Cabot (2014) makes similar findings in a different context, detailing how provision of pro bono legal assistance hinges on how far a potential client is deemed "eligible" for asylum by NGO-based assessors in Greece. For 
Cabot's interlocutors, these decisions are marked by moral-ethical dilemmas informed by popular and statist ideas that differentiate "refugees" from "migrants" as deserving of aid (Cabot 2014, 84-88). Carol's reflections imply that similar factors motivate her, and her colleagues' decisions regarding who to help - with two notable additional concerns guiding their choices. One is the difficulty of winning the case, which is quite distinct from eligibility for asylum. The second is a different strand of delineation between categories of migrant than that which Cabot encounters, namely between "sympathetic," "exciting" clients, and "run-of-the-mill" cases.

A nexus of racialized and gendered tropes about suitable and desirable immigrants informs these ideas, which here render LGBT Ugandans more readily offered aid than their straight, political dissident counterparts. Central Americans, those most commonly demonized and pathologized by U.S. politicians and media commentators as "a problem" (Brown 2013), are seen as unsympathetic and mundane. Such views cannot be read outside of the contemporary context, in which U.S. President Obama (2014) proclaimed that beneficiaries of immigration reform should be "families, not felons."

Media and NGO publications about LGBT asylum seekers additionally fueled these imaginaries. The frequently deployed refrain that LGBT claimants are 
people "persecuted because of who they are and who they love" (c.f RemediBrown 2014) assertively associates their suffering with their subjectivity, not their actions. This framing renders them passive victims in need of rescue from homophobic oppressors, obscuring that the persecution they faced may well have resulted from intentional and chosen activities, including LGBT rights advocacy. Naming LGBT claimants as "innocent" (cf. Harvey 2012) reemphasizes the point, while further differentiating them from other, imagined, immigrants.

As Miriam Ticktin (2011) suggests, the contemporary figure of the "genuine," sympathetic asylum seeker is deeply gendered, such that women have become the archetypal and preferred recipients of aid. Male asylum claimants, conversely, have become emblematic of the "bogus" asylum seeker, a figure popularly regarded as dangerously agentive (Griffiths 2015). These constructions feminize LGBT asylum seekers, and in particular gay men—who in governmental spaces are often seen as lacking credibility if they do not display suitably effeminate vulnerabilities (Johnson 2007; Kimmel and Llewellyn 2012). Carol's comments reveal that LGBT asylum seekers are similarly assessed and differentiated from spectral "unsympathetic" immigrants in non-governmental spaces.

\section{Credible}


At a 2014 public seminar in Washington, D.C., advertised as educating "stakeholders" on developments in LGBT asylum adjudication, audience members were asked to identify ourselves through a show of hands. I was one of three researchers, sat among five immigration attorneys, a dozen NGO or think tank staff, four LGBT asylum seekers or asylees, and six USCIS employees - one of whom announced that she was there to take notes for future Asylum Officer trainings. The first panel comprised of NGO and research center staff, including RIC Senior Attorney, Oliver Ho. In his presentation, Mr. Ho assertively argued that LGBT claimants' testimonies should hold more weight in the adjudication process because material evidence was particularly difficult to obtain in this type of case. His statement prompted a slew of follow-up questions from the audience.

The first asked Mr. Ho if he "had seen Asylum Officers evoke LGBT stereotypes when questioning a claimant?" A second noted "growing concerns" with "fraudulent claims" before asking: "what other methods would you suggest, to assess whether or not it is a legitimate claim?" Addressing both questions at once, Mr. Ho lamented that officials sometimes held "unfounded" views about LGBT people. "Not every gay person reads Oscar Wilde!" he joked, referencing a recent investigation into inappropriate questioning of LGBT asylum claimants in England. He continued, apparently responding to the second question: 
One thing that I do find is helpful is that all LGBT people have a narrative about coming out to themselves. Even if it involves intense self-hatred, if it involves intense discomfort, if it involves-and, you know, that's a story that people who are pretending to be queer, they just don't have as much of. You know, I hear a lot of-- I do encounter people who I simply don't believe. I think they are simply trying to have an asylum claim. I don't blame them. If you're one inch away from deportation, I understand why you would want to do that. But one thing that their story lacks is this sort of building block, that sort of development of a story. I hear a lot of people go, "you know I had sex with this guy and that made me gay!" and then you get someone who says: "look, I have no evidence but I can tell you about when I first had these feelings for a guy." I find that, as an attorney involved in these cases, as more credible.

"Credibility" is a key component of LGBT asylum claim adjudication. In the absence of other evidence, adjudicators can base their decision entirely on whether or not they find a claimant to be credible, or "authentic" (Middelkoop 2013; Murray 2016). Despite refuting stereotypical expectations of LGBT claimants, Mr. Ho asserted that all LGBT people do, in fact, have something in 
common: "a coming out narrative." By reminding the audience that he is both an expert and advocate for LGBT asylum seekers, Mr. Ho framed his opinion as accurate and empathetic. Yet he also revealed that he personally evaluates potential clients' credibility—effectively, how far he believes their story—on the basis of a particular trope concerning LGBT subjectivity. Audience members, USCIS representatives included, dutifully noted his advice.

Yet Mr. Ho's perspective ran counter to the lived experiences of many of my LGBT asylum seeker interlocutors. His assertion that a "coming out narrative" is an essential marker of LGBT identity reified a Western, neoliberal subject position informed by the experiences of white, U.S.-based gay men (Decena 2008b; Acosta 2008) The progressive linearity of Mr. Ho's idealized, universalized narrative — replete with "building blocks" and "development" from "intense self-hatred" to self-acceptance—-frames the normative LGBT asylum seeker as once closeted and miserable, but achieving stability and authenticity (or, "credibility") through the act of coming out.

This understanding of LGBT experiences echoes the "homosexual identity formation model" of Australian psychologist Vivian Cass (1979), which has been broadly embraced by adjudicators considering LGBT asylum claims (Berg and Millbank 2009). As Berg and Millbank argue, however, the framework is: "based 
upon a specific cultural and gendered experience of sexuality that may not be more broadly applicable, and that even within such caveats cannot adequately account for the diversity of human experience of sexuality" $(2009,207)$. By framing "fully formed" sexuality as "fixed and discoverable" (Berg and Millbank 2009, 208), the Cass model denies the fluidity of sexuality, supporting enduring understandings of bisexuality as a "primitive" expression of sexuality, or as a stepping stone on an incomplete journey (Hemmings 2007, 14). Developmental paradigms justify asylum adjudicators' pervasive suspicion of bisexual claimants (Rehaag 2009), and their expectations that LGBT claimants "prove" their sexuality — an expectation Mr. Ho ostensibly opposed. In underscoring his own conceptualization of "credible" LGBT subjectivity, however, Mr. Ho rendered further suspect those claimants whose experiences do not conform to (stereo)type.

Asylum officers' focus on claimants' childhood experiences and "discovery" of their sexuality as ostensible sources of credibility typifies how the stage model influences LGBT case adjudication. As Yasmin, a lesbian asylee from Tunisia, recalled of her asylum interview:

[The Officer] questioned me a lot about how I discover my sexuality, like he want to know. He know the story. He know the fact. [But] he want to be sure that I'm a lesbian, you know. The way 
I saw it, it was actually like three part[s]: First part childhood, like when I grew up and the way I know I'm a lesbian and everything, how people knows I'm a lesbian and [if] people been asking me if I'm a lesbian. He took a lot of time asking this question. It's been like whole interview focusing about that. He want to know if for real I'm lesbian or no. He been like, "I didn't understand that, one more time?"

For the interviewer, Yasmin's credibility hinged on her ability to convincingly elucidate - to borrow Mr. Ho's phrasing — a "narrative of coming out to herself," or of realizing she was a lesbian, "for real." Yet, as Eve Sedgwick reminds us, "many gay adults may never have been gay kids and some gay kids may not turn into gay adults" $(1990,42)$. Moreover, this is not Yasmin's volunteered narrative, but rather one that the interviewer prompts, then seeks to verify.

It is also the narrative that Yasmin had practiced under guidance from her lawyer, because she anticipated Yasmin's way of telling her story was unlikely to meet adjudicators' expectations. Attorneys regularly work with their clients on strengthening credibility, an experience that Nikolai, a gay man from Russia, found challenging, and unexpected. He had initially worked on his case independently, downloading forms from the USCIS website, collecting supporting 
documents, and translating his affidavit into English with the help of his friends. Before submitting his application, Nikolai emailed a legal clinic to ask if it could simply review his file. The clinic swiftly offered to take on his case, pro bono. His new lawyers say that he had a "strong" case-but the personal statement needed work. Nikolai explained:

They decided to rewrite my story. To put more emotions. I can't express my emotions generally. You know, I'm a gay, but I'm a man, and I'm Russian man, of course, so it's difficult to express your emotions. We spent like four meetings, totally eleven hours, I told my story. Everything what I remember, everything what happened to me. [...] they said, like, "it's so important to put more emotions. More your feelings.” They had some examples, from the professional attorneys. It took like two months more [to submit].

The attorneys guided Nikolai to replace his self-described Russian, gay, male subjectivity with a script that adjudicators had historically accepted as "authentic" for other claimants. By Nikolai's own assessment, the process was designed to feminize his subjective, (un)emotional response to persecution. Despite having a strong case, Nikolai's testimony was repackaged so that it reaffirmed 
adjudicators'—and, notably, his attorneys'—preexisting ideas about “credible" LGBT asylum seekers.

Such practices obscure that there are countless different ways of being sexual, and that people have countless different ways of, and reasons for naming themselves as belonging — or not— to a particular sexual identity category (Sedgwick 1990, 25). LGBT asylum seekers are no different. A person who is not read as "credibly" gay in the United States may well have been read as such elsewhere and suffered violent reprisals as a result: globally, LGBT (and non-“LGBT") people are persecuted not only because of their feelings or identities, but also because of their sexual activities - for what they do as well as, or in spite of, who they "are".

Applications for asylum submitted by, or on behalf of LGBT claimants frequently cite evidence of homophobic persecution in a particular country context. Despite probably referencing laws in their case files, both Nikolai's attorneys-privately, to their client—and RIC staff attorney Mr. Ho — in his public advocacy roleassertively distinguished between acts and feelings when assessing the credibility of claims. Yet, following Amanfi v. Ashcroft, persecution on the basis of perceived, or "imputed," homosexuality can provide grounds enough for asylum, regardless of how the claimant self-identifies. Within the constraints of the law, 
then, avenues to asylum should remain open to claimants who identify as bisexual, for example, or as any other same-sex desiring identity that is not encapsulated by “LGBT.” Mr. Ho's words foreclose that possibility.

In Greece, NGO-based lawyers recognized that their decisions regarding potential asylum seekers" eligibility for services did "exactly the same" work as the State (Cabot 2014, 98). Mr. Ho, in contrast, assertively differentiated his own ideas about "credible" LGBT subjectivity from those of government officials, which he further identified as problematic and in need of reform. Nikolai's attorneys, despite recognizing his as a sufficiently documented, "strong" case, reframed his character in keeping with their own ideas about credible subjects. These actions were not born of cynicism, nor of attempts to adhere to governmental directives. They were rather the result of deep investments in prevailing narratives about LGBT people and about "sympathetic" asylum seekers.

Over the course of my fieldwork, I found that pro bono attorneys who represented a broad range of clients were less concerned with LGBT "credibility" than their specialist counterparts. For example, Erica Jenkins, a senior attorney at New England Immigration Services (NEIS), a pro bono organization that worked with a variety of clients, explained her approach to LGBT asylum cases: 
[G]ood lawyers... would make the argument based on sexual orientation but also make any other collaborative claims, [because] maybe it's sometimes easier for a Judge to find that [the claimant] would face persecution on another basis. It's a harder case-it's not an impossible case but it is a more challenging case to kind of explain all these pieces.

Erica emphasized that she and her colleagues were "ideally" meant to present each case on its individual merits, rather than follow a generalized script. Recalling specific applicants, Erica further explained how factors including imputed identity, engaging in LGBT rights advocacy, or in partaking in activities that were banned on religious grounds could strengthen a claim such that adjudication would not hinge on whether a claimant appeared to be "really gay". Erica conceded that funding cuts and a subsequent lack of training and resources meant that NEIS lawyers struggled always to adopt this ideal approach—and that NEIS also primarily took on "winnable" cases, particularly when the organization was "overstretched." She concluded, nonetheless: "I would argue that you still have the obligation to present all of those aspects of a claim."

Scarcity of resources undoubtedly compels attorneys to make difficult, subjective decisions regarding whom to represent. High success rates can boost morale and 
attract donors to support a provably winning team. Competent representation undoubtedly helps some LGBT claimants who might otherwise struggle to successfully claim asylum. These caveats should not, however, obscure the ideological positions of attorney-advocates who are deeply embroiled in the circulation of limited and limiting discourses about LGBT asylum seekers.

Specialist lawyers providing pro bono services at high profile NGOs are regarded by media commentators, engaged publics, and some State officials as expert voices on LGBT asylum seekers. RIC's attorneys have had particularly visible platforms, through campaign emails, webinars, press coverage, Op-Eds, and conference presentations. They also inform policy: RIC has formally consulted with USCIS to author directives and training manuals for adjudicators. RIC's stated aim is to reform the asylum system to better serve the needs of LGBT claimants. Such formal engagements may offer one pathway to that end. Yet, as the advice of its Staff Attorney Mr. Ho reveals, the RIC assessment of who may be seen as an LGBT asylum seeker is also partial, and is also informed by normative and Western perspectives - echoing, albeit in a slightly different tenor, the existing perspectives of U.S. State officials.

Funding cuts and demand for services have made it increasingly difficult for all asylum seekers — not only those who are LGBT — to secure legal representation, 
particularly if they are not regarded by potential providers as "sympathetic," "exciting," and/ or "credible", or if their cases are complex enough to require senior staff attention. Because adjudicators know and understand organizations' selection processes and criteria, merely securing representation-particularly if it is pro bono-renders an asylum seeker immediately legible as having a "strong" case. Failure to secure pro bono counsel, by extension, suggests otherwise. In this context, the statistical evidence that having qualified representation dramatically improves a claimants' chances of success (TRAC 2016) cannot be read as a simple causality. Instead, for some claimants, meeting non-governmental expectations has become the first hurdle in the asylum process.

\section{Foreclosed Subjectivities}

In the United States, asylum seekers cannot legally work until at least six months after submitting their claim, and are barred from accessing federal welfare programs. Unless they are well-connected or have substantial personal resources, they are extremely likely to experience poverty and homelessness. NGOs provide invaluable support to many. Yet discourses concerning LGBT asylum seekers circulate beyond legal service providers and throughout the NGO sector, influencing founders', workers', and volunteers' ideas about who are the most vulnerable and in need of aid. The NGOs at which I conducted my research were 
established to provide material support—housing, stipends, travel cards, educational programs, healthcare referrals, etc.—specifically and exclusively to LGBT asylum seekers.

These NGOs also conducted intake interviews — of varying levels of formality— with potential service users. At each one, having an attorney was a criterion for acceptance into the program, compounding the challenges faced by those who struggled, for any reason, to secure representation. Having a lawyer did not necessarily reduce scrutiny of individuals' experiences or subjectivities, however. At each site, those LGBT asylum seekers who did not conform to NGO workers' expectations often found their sexual subjectivity and histories subject to questioning, and rumor. As in the legal contexts addressed above, two behaviors in particular aroused suspicion: opposite-sex desire and hesitancy to disclose.

The Fallacy of the " $B$ "

According to its staff, the Program for LGBT Asylum Seekers (PLAS) in Nottsborough, New England, had never had a bisexual client. During my nine months at PLAS, however, it became clear that some clients had voluntarily engaged in opposite-sex relationships - and that some continued to do so. Mia, from Trinidad, was candid with me about her past relationships with men, but was 
regarded by PLAS volunteers as a lesbian. She was regularly introduced as such, because, she assumed, she had arrived with a female partner. Mia told me that she saw herself as a gay woman now, but could not disregard past, or possible future male partners. She did not correct PLAS workers' language or impressions, however, and was generally cautious about what they knew about her personal life. She was, she explained, fine "letting them draw their own conclusions" about her sexuality.

Given my conversations with PLAS staff, I understood Mia's attitude. Organizational leaders often confided with me that they could not know if a specific person was "really gay." None mentioned bisexuality, despite the " $\mathrm{B}$ " in their organization's name. An aura of distrust characterized many interactions between staff and clients, as former client Julia described:

Julia: There's this thing of people suspecting each other. "Oh, maybe so and so is not gay." So they are already in your business. But that one comes from [PLAS Director] Marcy. She asks you, "Do you think Kim is gay?" She asks anyone. If she is with you, she'll ask about me. If she's with me, she'll ask about you.

$M e$ : Where do you think that comes from? 
Julia: It comes from-- They-- This whole asylum thing-- I think they don't believe us and because they don't believe us, she makes us police each other. "Oh, do you think so-and-so is gay?" I had to tell her, "Don't ask me, I do not know." [...] I told her: "Stop asking me who is gay and who is not. I don't know. Ask them." Because I was tired of that kind of thing.

Julia's response prompted me to ask her thoughts on similar suspicion articulated within the U.S. asylum system in general, mentioning media framings of "bogus" claims LGBT identity made in order to obtain asylum. Julia scoffed at the idea, pointing out the complexity of asylum cases and reminding me that adjudicators expected claimants to provide physical and psychological evidence as well as extensive formal documentation of their claims. "When I was proving my case, a lot went into it. [...] It's not like they only listen to your story and close the book!" she exclaimed. A while later, however, Julia returned to the discussion to add: "But for saying 'I'm gay' when you're not? I don't think that's right. I think those who lie, they misuse the system."

Another PLAS client echoed her sentiment, volunteering without prompting in a separate interview that anyone who was "lying about being gay" in order to receive PLAS support was "taking the place of someone who really needs that 
help." Yet she, like Julia, was not really interested in other client's romantic lives, telling me: "that's their business. Like me, I don't like to tell my story, so why would I need to hear theirs?"

PLAS leaders adopted a different stance on questions of privacy and ambiguity. At speaking events and in its campaign literature, PLAS assertively referenced its LGBT asylum seeker clients' opposite-sex relationships "back home" as products of cultural obligation, forced marriage, or individuals' attempts to "hide who they really were." Jacques, a formerly wealthy businessman from West Africa, was one such client. In public speeches, co-authored with PLAS leader Marcy, Jacques referred to his marriage as "a sham" and "a cover for my sexuality." In private, he displayed an intense affective relationship with his wife, speaking with her daily, about their children and grandchildren and business matters. Jacques was not estranged from his wife, who had known about his same-sex, extramarital relationships for a considerable time before they were discovered by the authorities. Their relationship did not undermine Jacques' self-identification as "gay," but neither was it fully articulated under the rubric of a "sham marriage" eagerly left behind. Around PLAS leadership, however, Jacques was careful to stick to his script. 
Sadia, an Iranian asylee who self-identified as bisexual, told me matter-of-factly that she only selectively disclosed her sexuality, and was particularly cautious around "old friends" who had supported her through the asylum process. Then, she had been in a relationship with a woman, and had followed her attorney's advice to identify as lesbian, rather than bisexual, to avoid a "risky" complication. A year after receiving asylum, Sadia began a new, serious relationship with a man. They decided to move to a new city because Sadia feared her former supporters would "tell the authorities" if they discovered the relationship, and that it would "look like I lied, like, that I committed fraud." Despite her anxieties, Sadia was heavily involved in bisexual visibility campaigns and community groups online - albeit not under her full name. She explained:

Like, I'm proud to say I am a bisexual woman, and I think that it's important that people recognize bisexuality, and how the asylum system doesn't have room for that, just like LGBT communities have a problem with bisexuality, even though they have it in their names. But right now, I still have to be careful, because I can't just be an out and proud bisexual when it could get me sent back [to Iran]. 
As bisexuals' asylum claims are routinely rejected by U.S. adjudicators (Rehaag 2009), Sadia anxieties were well-founded. Notably, she did not differentiate between USCIS and her former community-based supporters when articulating her fear of discovery.

\section{Compulsory Disclosure}

A client not being "out," or being hesitant to openly and publicly disclose their sexuality, also caused consternation at PLAS — as it does in USCIS interview rooms (Morgan 2006; Murray 2016). At PLAS, being "in the closet” was habitually explained as a product of self-hatred or shame on the part of the asylum seeker. It was discussed as an obstacle to be overcome, in order not only to gain asylum but also — according to Marcy — to be "true" to oneself. As such, Marcy expressed dismay over those PLAS clients who chose to maintain ties to fellow nationals in the diaspora:

You know... it's their decision where they want to live and how they want to live. Some of the things that we've found is that, if they're not out to themselves... Which, if you were a woman in Africa, you would never say: "I. Am. Lesbian.” You would never say that. So, getting them to learn how to be out is really important. 
Marcy's words evoke a spatial framework of where she perceived it was safe to be "out," configuring "Africa" as a place where LGBT people are unable even to articulate their sexuality. Despite knowing multiple outspoken LGBT activists who had been highly visible in their home countries, Marcy repeatedly framed PLAS' work as "helping" LGBT asylum seekers to be out, "to themselves" and publicly.

She regularly outed PLAS clients without their consent, justifying her actions through an assertive moral geographic mapping of the United States vis-à-vis clients' countries of origin. As Katie recounted, recalling a social event that she had attended with the PLAS leader:

I'm like, "Marcy, why did you have to tell them [people at the event] that I'm a lesbian?" She's like, "Aren't you a lesbian?" I was like, "Yes, but you don't have to go and tell everybody that I'm 'a lesbian from Kenya'" and she's like, "Oh Katie, they're not going to do anything to you. This is America. You're safe."

Marcy's insistence can be read as an attempt to reassure herself, and others, that the United States is a "safe" place for LGBT people — in contrast with those countries she imagined, and evoked, as inherently homophobic. This 
"homonormative nationalist," or "homonationalist" (Puar 2007) framing justifies grants of asylum to LGBT claimants by asserting their need for protection. It also pathologizes particular, non-Western nations - and their other, non-LGBT citizens - as dangerously backwards. This maneuver effectively re-inscribes the spectral masculine, agentive, "unsympathetic" asylum seeker as a threat to the liberal nation— - justifying their exclusion. Marcy's views on disclosure did not reflect that of many PLAS clients, as Josephine, an asylee from Uganda, explained:

To be honest with you, I think this asylum thing kind of forced me to come out, because of the way it is really, but I felt like I wasn't doing it on my own pace. If I'm to do it on my own pace, at this point I'm just happy taking one day at a time, because I believe in my heart that whatever my sexuality is, is not anybody's business. So... will I come out in the future? Yeah, but, that depends on, like if I have a girlfriend and what they decide to do. It's very hard to be with someone who is out and you're not. Yeah, but, I'll make that decision when I get there. Right now, I'm happy being not out.

Josephine disclosed on a need to know basis—and felt that people rarely needed to know. Josephine and I spent little time discussing sexuality, relationships, or 
the details of her case. She, like all of my asylum seeker interlocutors, had other things going on that they felt were worthy of more attention. She also considered questioning people about their private lives to be "impolite." Former PLAS client Harrison echoed Josephine's sentiments, stating:

You won't find me going down the street public display of affection. For me, my sexuality does not define who I am. [...] I've been here since 2007, now I'm much more comfortable, in terms of more settled, but at the same time, I don't walk around with it [that I'm gay] on my forehead. Because that's my business.

For Marcy, however, public visibility remained essential. Herinsistence evokes Manolo Guzmán's insight that: “in the discursive context of [hegemonic] gay homosexuality, the love that once dared not speak its name becomes... the love that cannot stand not being not named"' (2006, 91, emphasis original).

In his discussion of men of color in the United States who do not self-identify as gay or bisexual but express same-sex desire, Carlos Decena further identifies "a regime of compulsory disclosure" within the country, such that "subjects who avoid coming out become a threat to mainstream U.S. society because they refuse regulation" (2008a, 405). Under this rubric, only out, non-ambiguously gay 
people may be considered "ethical sexual citizens." Decena's insight that: "psychological deficiency, and not political or sexual dissent, has been used to explain the behavior of people who cannot or will not come out" $(2008 \mathrm{a}, 406)$ further anticipates Marcy's attitude toward LGBT asylum seekers.

Mark Chaing's insight that "desire for both men and women can... only be narrated as a failure to become fully gay or lesbian, which is also to say fully transnational" (quoted in Hemmings 2008, 18) is particularly relevant in the context of asylum. Because being out connotes a stable, knowable, exclusively same-sex desiring subjectivity, bisexuality is further rendered suspicious — and dangerously out of step with (homo)nationalist ideals.

In order to settle their anxieties that the people they support are the right type of immigrant—deserving, suitable, unthreatening, trustworthy, vulnerable—PLAS required not only the private disclosure which is minimally expected in USCIS interview rooms, but additional, public proclamation. As such, its work extended beyond testing the eligibility of potential asylum seekers, to assessing their apparent suitability for U.S. society. 


\section{Conclusions}

I have shown how pro bono legal and specialist NGOs frequently (re)articulate, enact, and extend limited and limiting governmental logics and hegemonic discourses concerning LGBT asylum seekers. Their investments in homonormative, Western-informed ideas about LGBT subjectivity_particularly that sexuality is immutable, and that coming out is both necessary and inevitable - function simultaneously to regulate individuals seeking asylum, to reaffirm the expectations of USCIS officers adjudicating asylum claims, and to reassert homonationalist imaginaries within, and of, the United States.

These investments have a detrimental impact on individual LGBT asylum seekers, as those who do not meet service providers' expectations or organizational goals can struggle to secure support and, consequently, asylum. Those who do obtain NGO support may nonetheless endure ongoing surveillance and suspicion in spaces that are, ostensibly, beyond the purview of the State. In order to be fully accepted, as honest, deserving immigrants with the potential to become an ethical citizen, LGBT asylum seekers must meet particular expectations which are embedded in neoliberal, homonormative ideals. Namely, they must become recognizable as belonging to the iteration of "LGBT" that indexes an out, white, middle-class, productive citizenry. 
The popularized image of LGBT asylum seekers also impacts the shape of asylum more broadly, as it pertains to all potential claimants. The exemplary LGBT applicant is constructed within a discursive nexus that situates them as different from agentive, masculine, unsympathetic, threatening immigrants; as the "good gay (potential) citizen" who is always already measured against the spectral, homophobic and illiberal other. In the contemporary context, this schema fuels rather than contests restrictive immigration policies in which specific nationals are seen as incompatible with U.S. society. As such, NGO-based advocates can be read as an extension of, rather than a reformist challenge to State efforts to restrict asylum to suitably "deserving" claimants.

${ }^{1}$ Depending on the circuit, case approval rates fluctuate between forty and sixty percent. 


\section{References Cited}

Acosta, Katie L. 2008. "Lesbianas in the Borderlands: Shifting Identities and Imagined Communities." Gender and Society 22 (5): 639-659.

Brown, Hana E. 2013. "Race, Legality, and the Social Policy Consequences of Anti-Immigration Mobilization." American Sociological Review 78 (2): 290-314.

Bell, David, and Jon Binnie. 2000. The Sexual Citizen: Queer Politics and Beyond. Cambridge. UK: Polity Press.

Berg, Laurie, and Jenni Millbank. 2009. "Constructing the Personal Narratives of Lesbian, Gay and Bisexual Asylum Claimants." Journal of Refugee Studies 22 (2): 195-223.

Berger, Susan A. 2009. "Production and Reproduction of Gender and Sexuality in Legal Discourses of Asylum in the United States." Signs 34 (3): 659-685.

Cabot, Heath. 2014. On the Doorstep of Europe: Asylum and Citizenship in Greece. Pennsylvania: UPENN Press.

Cass, Vivian. 1979. "Homosexual Identity Formation: A Theoretical Model." Journal of Homosexuality 4 (3): 219-235.

Decena, Carlos U. 2008a. "Profiles, Compulsory Disclosure and Ethical Sexual Citizenship in the Contemporary USA." Sexualities 11 (4): 397-413.

Decena, Carlos U. 2008b. "Tacit Subjects." Gay and Lesbian Quarterly 14 (2-3): 339-359.

Duggan, Lisa. 2002. "The New Homormativity: The Sexual Politics of Neoliberalism." In Materializing Democracy: Toward a Revitalized Cultural Politics, edited by Russ Castronovo and Dana D. Nelson. Durham, NC: Duke University Press.

Griffiths, Melanie. 2015. "'Here, Man is Nothing!": Gender and Policy in an Asylum Context." Men and Masculinities 18 (4): 468-488. 
Harvey, Janice. 2012. "When Very Bad Things Happen to Innocent People." Worcester Magazine. October 18, 2012.

Hemmings, Clare. 2007. "What's in a Name? Bisexuality, Transnational Sexuality Studies and Western Colonial Legacies.” The International Journal of Human Rights 11 (1-2): 1332.

Johnson, Toni A. M. 2007. "Flamers, Flaunters and Permissible Persecution.” Feminist Legal Studies 15: 99-111.

Kimmel, Michael, and Cheryl Llewellyn. 2012. "Homosexuality, Gender Nonconformity, and the Neoliberal State." Journal of Homosexuality 59 (7): 1087-1094.

Lewis, Rachel. 2013. "Deportable Subjects: Lesbians and Political Asylum." Feminist Formations 25 (2): 174-194.

Middelkoop, Louis. 2013. "Normativity and Credibility of Sexual Orientation in Asylum Decision Making." In Fleeing Homophobia: Sexual Orientation, Gender Identity and Asylum, edited by Thomas Spijkerboer, 154-175. Abingdon, United Kingdom: Taylor \& Francis.

Morgan, Deborah A. 2006. "Not Gay Enough for the Government: Racial and Sexual Stereotypes in Sexual Orientation Asylum Cases." Law \& Sexuality 15: 135-161.

Murray, David A.B. 2016. Real Queer? Sexual Orientation and Gender Identity Refugees in the Canadian Refugee Apparatus. London: Rowman and Littlefield.

Obama, Barak. 2014. "Remarks by the President in Address to the Nation on Immigration." Washington, DC: The White House Office of the Press Secretary.

Puar, Jasbir. 2007. Terrorist Assemblages: Homonationalism in Queer Times. Durham NC: Duke University Press. 
Rehaag, Sean. 2009. "Bisexuals Need Not Apply: A Comparative Appraisal of Refugee Law and Policy in Canada, the United States, and Australia." International Journal of Human Rights 13 (2): 415-436.

Remedi-Brown, Fern. 2014. "Boston Pride Still Not Safe." Guardian Liberty Voice, 15 June 2014. http://guardianlv.com/2014/06/boston-pride-still-not-safe/.

Sedgwick, Eve Kosofsky. 1990. The Epistemology of the Closet. Berkeley, CA: University of California Press.

Stychin, Carl F. 2004. "Same-Sex Sexualities and the Globalization of Human Rights Discourse." McGill Law Journal 49 (4): 951-968.

TRAC. 2016. "Continued Rise in Asylum Denial Rates: Impact of Representation and Nationality.” TRAC, Syracuse University. December 13, 2016.

Ticktin, Miriam. 2011. "The Gendered Human of Humanitarianism: Medicalising and Politicising Sexual Violence." Gender \& History 23 (2): 250-265. 